\title{
EL SOL COMO INSPIRACIÓN DEL DISEÑO BIOMIMÉTICO
}

Pilar, Claudia A.

Instituto de Investigaciones Tecnológicas para el Diseño Ambiental del hábitat Humano (ITDAHu).

Facultad de Arquitectura y Urbanismo - Universidad Nacional del Nordeste (FAU - UNNE). Av. Las

Heras No 727 - 3500 - Resistencia -Chaco - República Argentina. Tel. $0054-0362$ - 4420088.

E-mail: claudiapilar2014@gmail.com

\section{RESUMEN}

La vida sobre la Tierra depende de la luz solar. El sol de manera directa o indirecta es la fuente de energía de la que derivan todas las demás.

La fotosíntesis es el proceso por el cual las plantas verdes y ciertas algas y bacterias toman dióxido de carbono, agua y luz y transforman todo ello en oxígeno y azúcares. De esta manera la energía solar, se convierte en energía química, fijando el carbono en compuestos orgánicos.

Este proceso resulta la fuente de inspiración para la energía fotovoltaica. Los sistemas solares fotovoltaicos convierten la luz solar directamente en electricidad, sin producir emisiones ni ruidos. En estos sistemas se "usa" un recurso sin agotarlo, sin afectar su calidad ni cantidad para las generaciones futuras. Su relevancia para la tecnología de la arquitectura está dada por su alto nivel de posibilidades de integración edilicia, siendo actualmente un desafío de diseño.

El ser humano desde sus inicios, basó sus innovaciones tecnológicas en la observación de la naturaleza que le ha dado tanto los recursos materiales como la inspiración para resolver sus necesidades de cobijo y protección, que con el paso del tiempo se fueron complejizando aumentando los requerimientos de confort.

La biomimética, como disciplina del diseño, es una rama de la ciencia que le aporta al hombre un método para resolver problemas. Permite aprender de las formas y procesos naturales, propiciando la creación o adecuación de soluciones tecnológicas cada vez más sostenibles y ambientalmente más conscientes. Ésta es de carácter eminentemente interdisciplinaria, dado que para comprender la naturaleza el método de abordaje debe ser holístico.

El presente artículo analiza la energía solar fotovoltaica como un proceso bio-inspirado y ambientalmente sustentable, que resulta un desafío para la innovación y el diseño tecnológico arquitectónico. Para ello se analizan casos de edificios que integran la energía solar fotovoltaica como mecanismo de generación de energía.

PALABRAS CLAVES: bioinspiración, sistemas fotovoltaicos, integración arquitectónica

\section{INTRODUCCIÓN}

Una de las facetas más visibles de la insustentabilidad ambiental de la construcción del hábitat es el alto consumo energético.

Las energías alternativas o renovables se convirtieron en una preocupación generalizada a nivel mundial a partir de la crisis del petróleo de 1973. Asimismo, junto con la toma de conciencia respecto al agotamiento de los recursos energéticos tradicionales también comenzó a manifestarse la preocupación por la preservación ambiental. En este contexto se creó el Programa de Naciones Unidas para el Medio Ambiente (PNUMA) que ha ido consolidando su relevancia internacional con la realización de la "Cumbre de la Tierra" (Río de Janeiro, 1992) y la firma del Protocolo de Kyoto sobre el cambio climático (1997). Desde entonces en la mayoría de los países del mundo se han impulsado programas de investigación y desarrollo de energías renovables para enfrentar el desafío que supone reemplazar el uso de petróleo y gas natural y reducir la emisión de gases efecto invernadero, y 
promovieron políticas de incentivo a las energías renovables y el uso racional de la energía (Garrido et al., 2014).

Las energías renovables pueden ser eólica, la solar, la minihidráulica, entre otras. Pero desde un punto de vista arquitectónico la energía solar reviste especial interés, dado la posibilidad de integrarla a la envolvente como cerramiento, que adecuadamente resuelto, permitiría cambiar la concepción de que los edificios consumen energía, pasando a una nueva situación en la que además la generan.

\section{DESARROLLO}

\subsection{Fotosíntesis como proceso inspirador}

La vida sobre la Tierra depende de la luz solar y todas las fuentes de energía derivan de forma directa $o$ indirecta del sol.

La fotosíntesis es el proceso por el cual las plantas verdes y ciertas algas y bacterias toman dióxido de carbono, agua y luz y transforman todo ello en oxígeno y azúcares. De esta manera la energía solar, se convierte en energía química, fijando el carbono en compuestos orgánicos.

En la fotosíntesis, las plantas captan la energía solar para nosotros y lo almacenan en forma de combustible. Para liberar esa energía, quemamos las propias plantas o productos vegetales ya sea internamente, en nuestra células o externamente, con fuego (Benyus, J., 2012). Cuando quemamos petróleo o carbón, liberamos a la atmósfera grandes cantidades de dióxido de carbono fijados desde el periodo cretáceo, incrementando el problema del efecto invernadero.

El ser humano desde sus inicios, basó sus innovaciones tecnológicas en la observación de la naturaleza que le ha dado tanto los recursos materiales como la inspiración para resolver sus necesidades de cobijo y protección, que con el paso del tiempo se fueron complejizando aumentando los requerimientos de confort.

La biomimética, como disciplina del diseño, es una rama de la ciencia que le aporta al hombre un método para resolver problemas. Permite aprender de las formas y procesos naturales, propiciando la creación o adecuación de soluciones tecnológicas cada vez más sostenibles y ambientalmente más conscientes. Ésta es de carácter eminentemente interdisciplinaria, dado que para comprender la naturaleza el método de abordaje debe ser holístico.

En lo que atañe a la arquitectura, consecuentemente con estas problemáticas, se está orientando el esfuerzo hacia la búsqueda de soluciones de diseño más eficaces, proyectos más eficientes que puedan lograr un equilibrio entre lo humano y la naturaleza, etc., lo que ha dado lugar a una nueva tendencia que se conoce como Arquitectura Biomimética (de "bio" = vida, y "mimesis" = imitar).

En la actualidad el enfoque biomimético no pretende extraer cosas de la naturaleza, sino aprender de ella (Benyus, J. 2012). Por ello arquitectura biomimética avanza mucho más allá de la simple imitación de las formas naturales, porque además se detiene a analizar los diversos procesos naturales, haciendo que las instalaciones de los edificios se comporten de una manera semejante, favoreciendo de este modo las condiciones de habitabilidad y confort, optimizando la estabilidad y duración de los edificios, y aplicando criterios de ahorro energético y mantenimiento.

Concretamente, la Arquitectura Biomimética nos acerca a un diseño más natural, tomando en cuenta las estrategias y soluciones que utiliza la naturaleza, aplicándolas en varios aspectos, creando diseños más naturales, ahorrando y haciendo más eficiente el uso de los recursos, sin agotarlos.

De acuerdo Benyus, 2012, las estrategias y principios de la naturaleza que nos sirven de inspiración son:

- Cabalga sobre la luz solar

- Gasta solo la energía que necesita

- Ajusta la forma a la función

- Lo recicla todo

- Premia la cooperación

- Cuenta con la biodiversidad

- Demanda la tecnología local 
- Frena los excesos desde dentro

- Saca partido de las limitaciones

Entre estas características los dos primeros aspectos resultan fundamentales y determinantes para justificar la necesidad de estudiar la energía solar como la fuente de energía privilegiada a captar en todo diseño biomimético.

\subsection{La energía solar}

Los sistemas solares fotovoltaicos convierten la luz solar directamente en electricidad, sin producir emisiones ni ruidos. En estos sistemas se "usa" un recurso sin agotarlo, sin afectar su calidad ni cantidad para las generaciones futuras. Las energías renovables actualmente ocupan un lugar importante en la matriz energética mundial, aportando aproximadamente un cuarto de la misma (REN 21, 2016).

El crecimiento ha sido sostenido en los últimos años e impulsado por la implementación de políticas de incentivos y de promoción para la generación de energía limpia.

Más de 100 países aplican políticas de apoyo a las energías renovables teniendo como principal fundamento las ventajas ambientales, pero también para fortalecer el empleo, el desarrollo económico y tecnológico (REN21, 2016).

En el concierto internacional las distintas organizaciones formales e informales de países muestran un compromiso con el desarrollo sustentable, incluyendo en sus agendas objetivos referidos a las energías sostenibles. Los sectores empresarios y de inversionistas también declaran su interés en el sector exhortando a los gobiernos a implementar políticas que apoyen a las energías renovables. Incluso los sectores religiosos en los últimos años expresan su preocupación por el cambio climático y el interés por lograr políticas de desarrollo más sustentables con énfasis en la energía (se destaca la encíclica del Papa "Laudato Si", así como la islámica, hindú y budista).

La energía solar Fotovoltaica (FV) posee un ritmo de crecimiento mayor que el resto de las energías renovables. La tasa de crecimiento de la energía solar fotovoltaica para el período interanual 2014 2015 fue del 25\%, ubicándose muy por encima de los demás tipos. En términos prácticos esto equivale a un número estimado de ciento ochenta y cinco millones de paneles solares.

En una década la capacidad mundial FV se incrementó diez (10) veces (REN 21, 2016) favorecido por las mejoras tecnológicas que ocasionaron una importante disminución en los costos de los módulos así como del resto del sistema (IRENA, 2016). Además de su reconocida faceta ambiental, la utilización de tecnología FV para la generación de energía eléctrica se ha vuelto competitiva desde el punto de vista económico y técnico para países desarrollados y paulatinamente para países en vías de desarrollo, siendo estos últimos los casos de mayor interés desde el punto de vista del mercado.

\subsection{Integración Arquitectónica de Sistemas Fotovoltaicos}

Desde un punto de vista arquitectónico la energía solar reviste especial interés, por sus posibilidades de integración a la envolvente, emulando a la naturaleza que se sustenta exclusivamente de este tipo de fuente energética.

La integración arquitectónica de instalaciones fotovoltaicas se contrapone a la generación concentrada de energía (que requiere de grandes superficies de terreno, generalmente lejos de los puntos de consumo) y permite usar la envolvente arquitectónica como sustento para la captación y generación de energía. Esto puede darse en cualquier parte de la piel del edificio (techo, fachada, marquesina, parasoles, superficies acristaladas, espacios semicubiertos, etc.) con el propósito de lograr una generación distribuida, disminuyendo las pérdidas por distribución.

La experiencia internacional nos presenta un abanico de ejemplos y experiencias que permiten desmitificar la idea de que la instalación fotovoltaica genera un impacto visual negativo. Por el contrario puede ser un recurso estético que mejore la morfología de los edificios, convocando la necesidad de un abordaje interdisciplinario. 
"La integración fotovoltaica en edificios (BIPV - Builidin Integrated Photovoltaics) supone la sustitución de materiales convencionales de construcción por nuevos elementos arquitectónicos fotovoltaicos que son generadores de energía" (FENERCOM, 2009). Los beneficios desde un punto de vista tecnológico constructivo de los sistemas fotovoltaicos integrados en edificios, siguiendo a Chivelet y Fernández Solla (2007), son:

- No producen ruido.

- No incluyen partes móviles (aunque existen sistemas de seguimiento solar, que podrían contradecir este postulado).

- Son modulares y fácilmente manejables como elementos de construcción.

Ahora, si lo consideramos desde un punto de vista global, son un aporte de energía limpia sin emisión de dióxido de carbono (CO2), un medio de concientización de la familia, la comunidad y la ciudad, y un aporte desde "abajo hacia arriba" en el camino que acerque a la arquitectura y el urbanismo a la sustentabilidad ambiental.

Por otra parte, el gran avance que ha tenido la industria FV en el desarrollo de materiales cada vez más atractivos para aplicar en el diseño arquitectónico de los edificios favorece la investigación, el desarrollo, la industria, la generación de empleo, entro otros aspectos positivos. El diseño integral supone un análisis del emplazamiento, diseño de la instalación, ejecución de la instalación y mantenimiento y el adecuado estudio de las sombras (uno de los factores que más pérdidas potenciales de radiación supone).

\subsection{Las características de la Región Nordeste de la Argentina}

Desde el punto de vista arquitectónico la alta radiación solar de nuestra zona es un problema de diseño dado que genera un alto disconfort del ser humano y exige la adopción de estrategias bioclimáticas para el diseño y materialización de la envolvente, tendiendo a la protección de aberturas y la proyección de sombras para resguardar los espacios habitables del exceso de ganancia solar. Incluso en muchos casos es necesario diseñar mecanismos para proteger a la propia envolvente del edificio y sus partes y materiales constitutivos, cuya durabilidad se ve afectada por la acción nociva de los rayos ultravioletas (UV).

Utilizar la energía solar excesiva para generar energía eléctrica sería una "inversión de signo" convirtiendo un problema (de diseño y construcción) en parte de la solución (protección solar) con una externalidad muy positiva, es decir proteger del exceso de radiación solar y transformar ese exceso en energía útil para el desarrollo de la vida del hombre.

La propia tecnología fotovoltaica (paneles y módulos FV) podría actuar -con un adecuado diseñocomo dispositivos arquitectónicos que permitan controlar el exceso de ganancia solar, a la vez que capta esa energía y la convierte en útil no sólo para el propietario de la vivienda o edificio en cuestión, sino de cualquier usuario conectado a la red (pensemos en parasoles solares integrados al diseño arquitectónico o la adopción de "techos sombra fotovoltaicos").

En síntesis, la integración de mecanismos de captación de energía solar en la envolvente constructiva podría resolver de forma simultánea dos problemas del diseño arquitectónico ambientalmente consciente:

- Regulación de la ganancia solar excesiva, propia de nuestra región bioclimática (zona bioamiental I - Muy Cálida, IRAM 11.603), a partir de la incorporación de paneles FV a modo de parasoles, fachadas dobles, techos sombra, etc.

- Generación de energía limpia y que además pueda ser utilizada in situ o por cualquier usuario de la red. Esto resulta de especial interés dado que por la materialización deficiente de la envolvente arquitectónica de un alto porcentaje de las construcciones de la región, la ineficiencia energética de la envolvente se suplanta con medios mecánicos de acondicionamiento, lo que genera altísimos consumos de energía (proveniente principalmente de fuentes convencionales).

Desde un punto de vista económico, si bien la tecnología FV sigue siendo onerosa, ha disminuido drásticamente sus costos. Este fenómeno es conocido como "Efecto Swanson", y la consecuencia 
práctica es la disminución del costo de los módulos FV cien veces desde al año 1977 a la actualidad (midiendo la relación dólar sobre watt producido). La caída de los costos de generación permitió que durante el periodo 2004 - 2013, se aumente la producción de energia FV a nivel mundial de 3,7 a 139 Gigawatt, es decir, multiplicándola treinta y siete veces en un período de diez años (REN 21, 2014).

\subsection{Análisis de casos}

Prácticamente no existen limitaciones en cuanto a la tipología de edificios que pueden integrar sistemas para captación de energía solar. La tecnología FV puede ser utilizada en viviendas, edificios en altura, edificios públicos y privados e incluso para la materialización de equipamiento y mobiliario del espacio público

Un caso de incorporación de un sistema fotovoltaico a gran escala en el espacio público lo representa la Solar Plant Forum Barcelona, construida en el 2004 en el marco del "Foro Universal de Culturas", como parte de una intervención mayor, recuperando un sector antiguamente destinado a planta de tratamiento de alcantarillado del sector costero de Barcelona, España. La iniciativa fue promovida por el Instituto para la Diversificación y Ahorro de la Energía (IDEA), el Ministerio de Industria, Comercio y Turismo y llevada adelante por el equipo de arquitectos José Antonio Martinez Lapeña y Elias Torres. Un total de 2.686 paneles fotovoltaicos cubren la gran superficie, generando una potencia equivale a la que necesitan 1.000 hogares y a un ahorro en emisiones de dióxido de carbono de 440 toneladas al año. La tecnología utilizada es la Conexión a Red (ver figura 1).
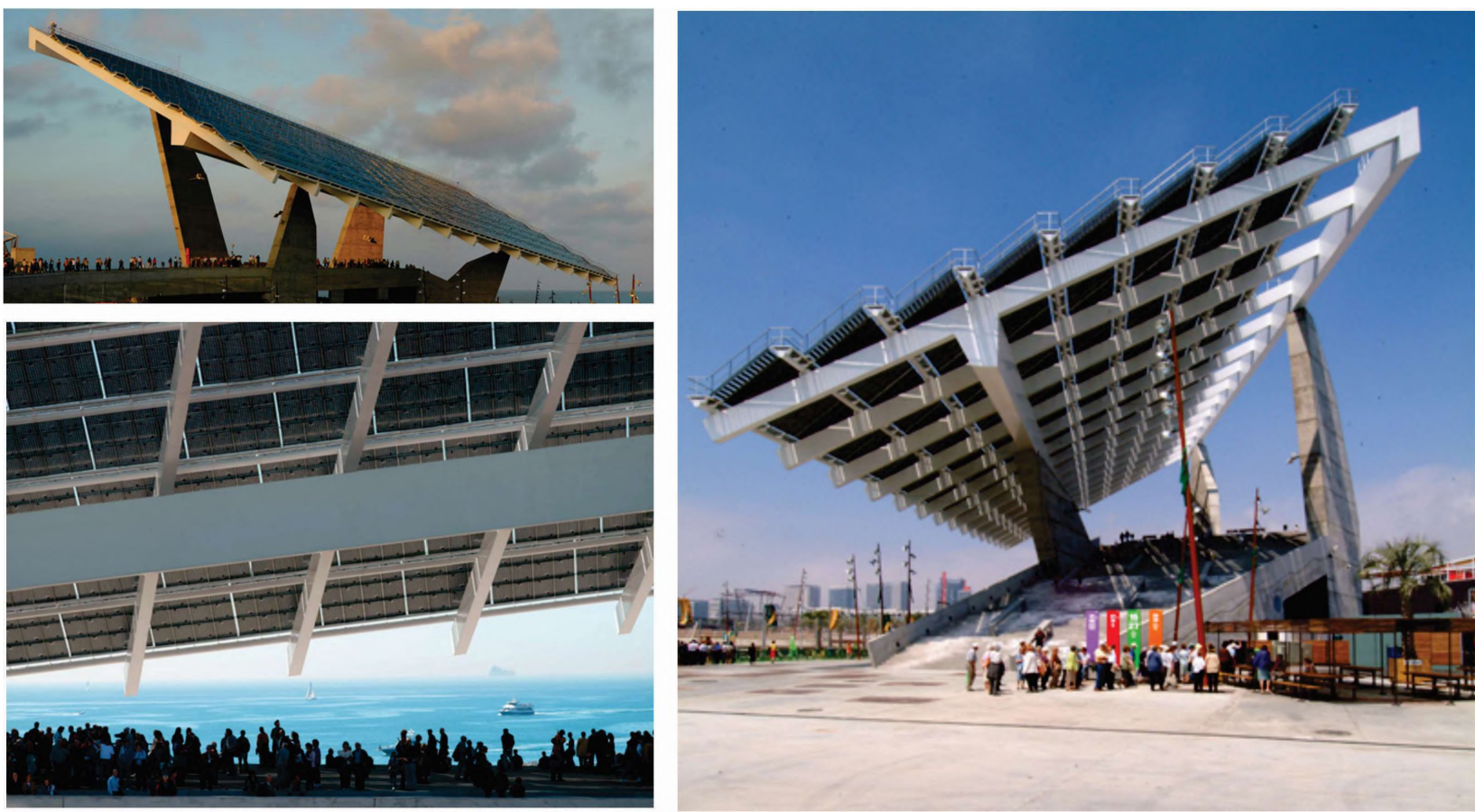

Fig. 1. Distintas imágenes de la pérgola que muestran la escala de la intervención. Fuente: http://arquitectes.coac.net/jamlet/projects/01_publicspace/PS17/index.html

Otros ejemplos de intervenciones urbanas fotovoltaicas, en una escala más pequeña, lo representan el Parque de les Basses de Sant Pere, en Sant Just Desvern, Barcelona, España (Figura 2 a la izquierda) y la Pérgola Parque Tecnológico de Andalucía, en Málaga, España (Figura 2 a la derecha). 

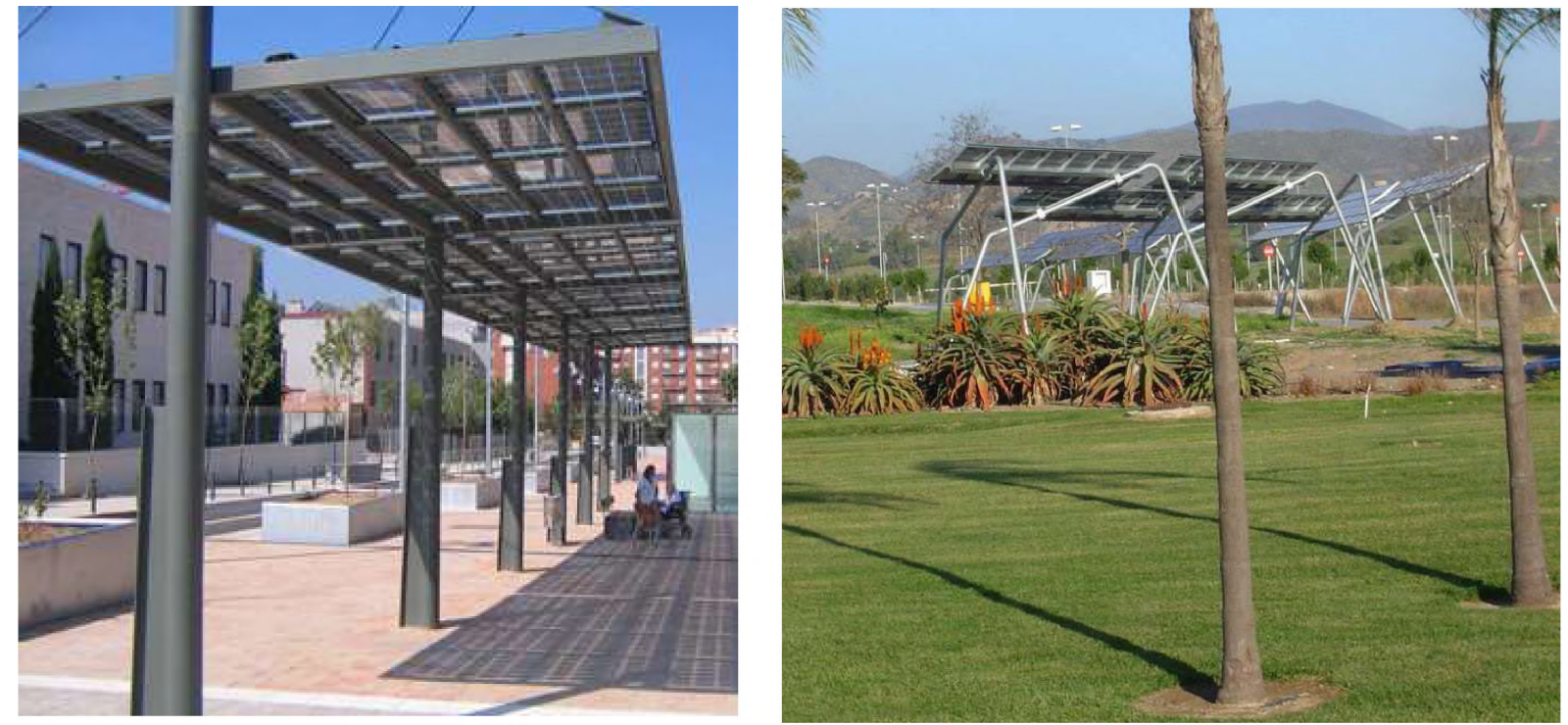

Fig. 2: a La izquierda el Parque de les Basses y a la derecha imágenes del Parque Tecnológico Andalucía.

Fuente: izquierda: http://www. construible.es y derecha: http://solenarq.com.ar/ppt-andalucia/

Un caso de integración arquitectónica FV en un edificio de gran superficie lo representa el Parque Tecnológico, Palmas Altas, que resultó del concurso internacional de ideas, para dotar de un espacio innovador y vanguardista a Abengoa, empresa dedicada al sector energía desde la sostenibilidad. La propuesta arquitectónica del Parque Tecnológico Palmas Altas está diseñado "para ser un nuevo "referente" en arquitectura sostenible. Un proyecto que va más allá de las caracteristicas típicas de un parque empresarial y busca convertirse en una auténtica comunidad compacta agrupada en torno a una plaza" (Pastorelli, 2010).

Su construcción se llevó a cabo en el año 2009 siendo diseño de los Arq. Richard Rogers, Arq. Luis Vidal \& Asociados. La superficie del emprendimiento es de $42.100 \mathrm{~m} 2$ y posee un total de 1.300 plazas de estacionamiento. Ver figura 3.
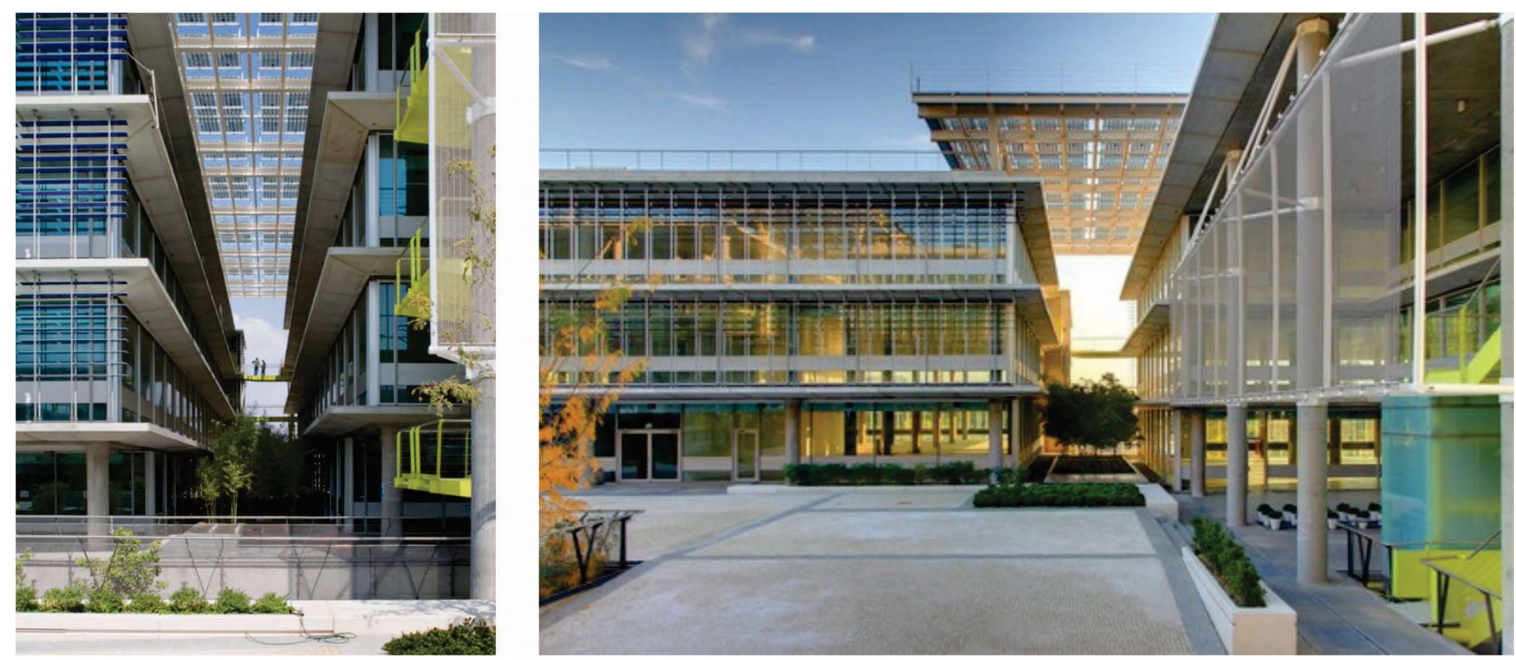

Fig. 3. Distintas imágenes del Parque Tecnológico, Palmas Altas, donde se observa la envolvente fotovoltaica. Fuente: https://www.rsh-p.com/projects/campus-palmas-altas/

Dentro de la misma tipología de edificios el Edificio de SMA Solar Academy, en Niestetal, Alemania, representa un ícono de la energía solar FV. Se trata de un edificio construido en 2010, de carácter futurista diseñado por el estudio de arquitectura HHS Planer + Architekten AG, que se encuentra 
independizado de la red mediante un suministro de energía renovable compuesto por una planta fotovoltaica auxiliada por otra de cogeneración de biogás.

La envolvente fotovoltaica incluye cubierta y fachada. En la figura 4 a la izquierda se puede observar la morfologia general de la propuesta sobreelevada en pilotes que aumenta la "ligereza visual" de la propuesta. En la figura 4 a la derecha se percibe la espacialidad que le otorga la fachada fotovoltaica traslúcida al interior del edificio.
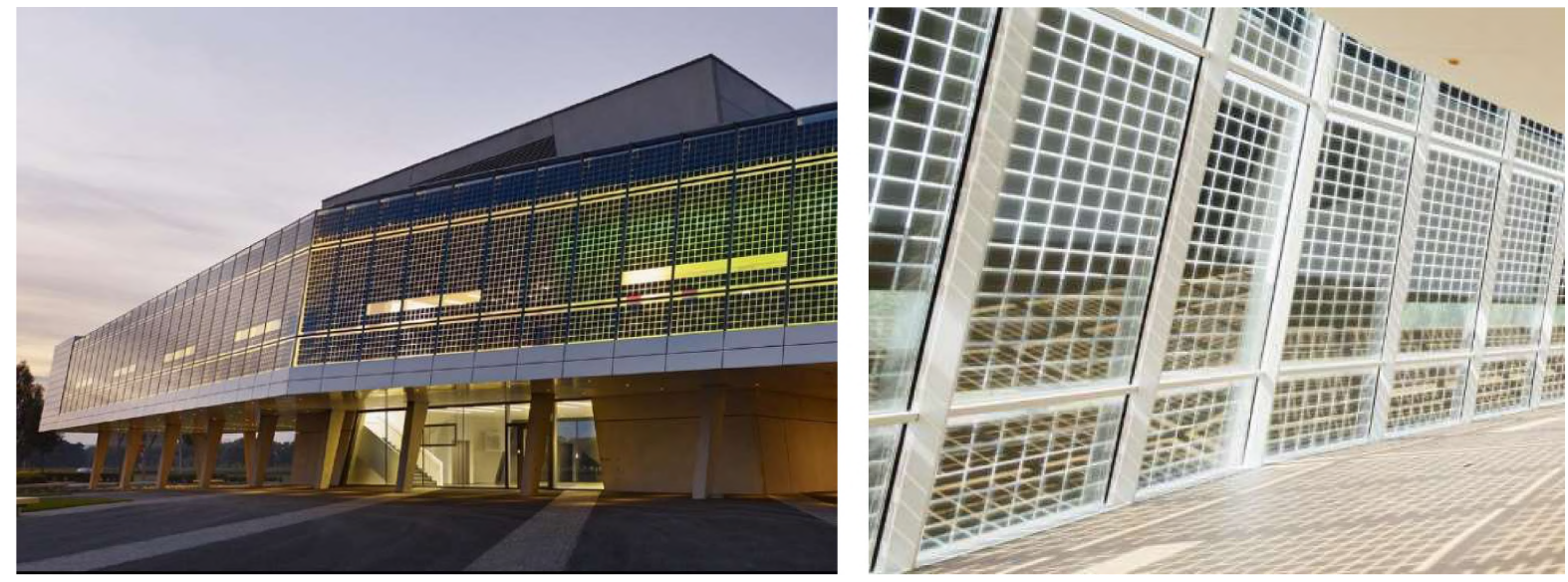

Fig. 4. La envolvente fotovoltaica del edificio SMA lo caracteriza y al mismo tiempo lo provee de energia. Fuente https://www.hhs.aq/proiekte. html?proiekt=solar-akademie\&tvpologie

Los sistemas FV también pueden ser integrado en edificios en altura como ser el caso del "Rascacielos Intesa Sanpaolo" de Renzo Piano, ubicado en la ciudad de Turín, Italia, inaugurado en el año 2015 cuyo fin es el de oficinas de la entidad financiera que le da el nombre.

Ha obtenido la certificación LEED Platino, en función de las múltiples aspectos de sostenibilidad que contempla. Entre ellos se destaca la superficie de fachada orientada hacia el sur (orientación expuesta para Italia) que como puede observarse en la figura 5 está enteramente cubierta por 1600 metros cuadrados de células fotovoltaicas para producir electricidad, mientras que el agua caliente se produce por un sistema de colectores solares.

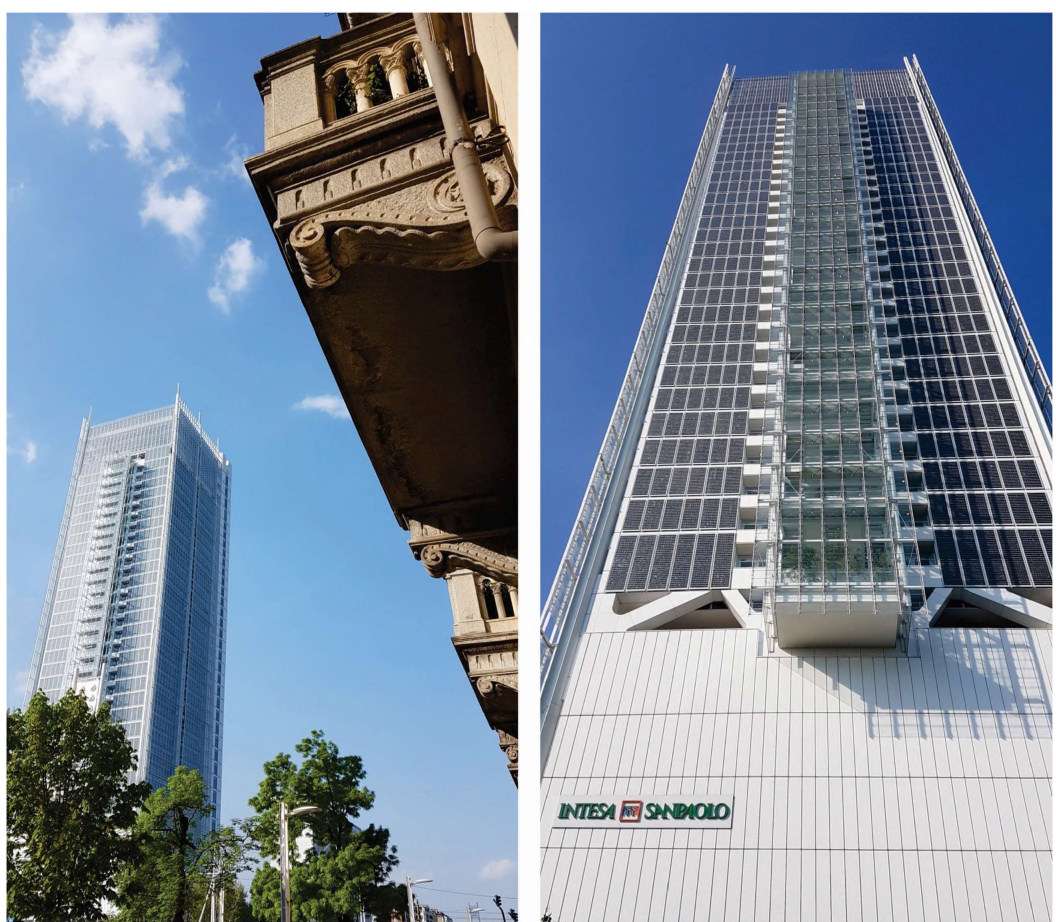

Fig. 5. Imágenes del Rascacielos Intesa Sanpaolo, de Renzo Piano. Fuente: elaboración propia. 
Los sistemas FV pueden ser usados también en edificios de vivienda e incluso en remodelaciones, como ser el caso del Solar Umbrella House, que es la vivienda particular de los autores de la obra Arq. Lawrence Scarpa y Arq. Angela Brooks, que remodelaron y ampliaron un bungalow construido en el año 1923. Se ubica en Venice, California, Estados Unidos y la última intervención se realizó en el año 2006.

Se inspira en la "casa paraguas" de Paul Rudolph de 1953, llevando la protección solar a un nuevo nivel conceptual en la que el amparo solar de diseño pasivo, es al mismo tiempo una generación activa de energía. Eso da como resultado una vivienda energéticamente neutral.

Los arquitectos eligieron paneles solares policristalinos, de color azul vivo, tratados como objetos de arte, generando una continuidad entre el techo y una fachada.

El parasol caracteriza el diseño, le otorga significado y materializa la intención principal referida a la sostenibilidad ambiental general de la propuesta. Los límites entre espacios interiores y exteriores se desdibujan permitiendo el disfrute del espacio exterior prácticamente todo el año como puede observarse en la figura 6. El sistema de paneles solares se encuentra conectado a la red y la inversión inicial se amortizó relativamente rápido, convirtiendo a los arquitectos-usuarios en prosumidores (Tofler, 1980).

Además de la energía solar fotovoltaica la casa incluye sistemas de retención de agua, reutilización de materiales, entre otros aspectos tendientes a la sustentabilidad ambiental. El diseño considera a la sustentabilidad como una dimensión ineludible y transversal de diseño, dando como resultado una armónica respuesta entre lo construido y la naturaleza. Un proyecto integral, holístico, demostrativo y ecológicamente militante.
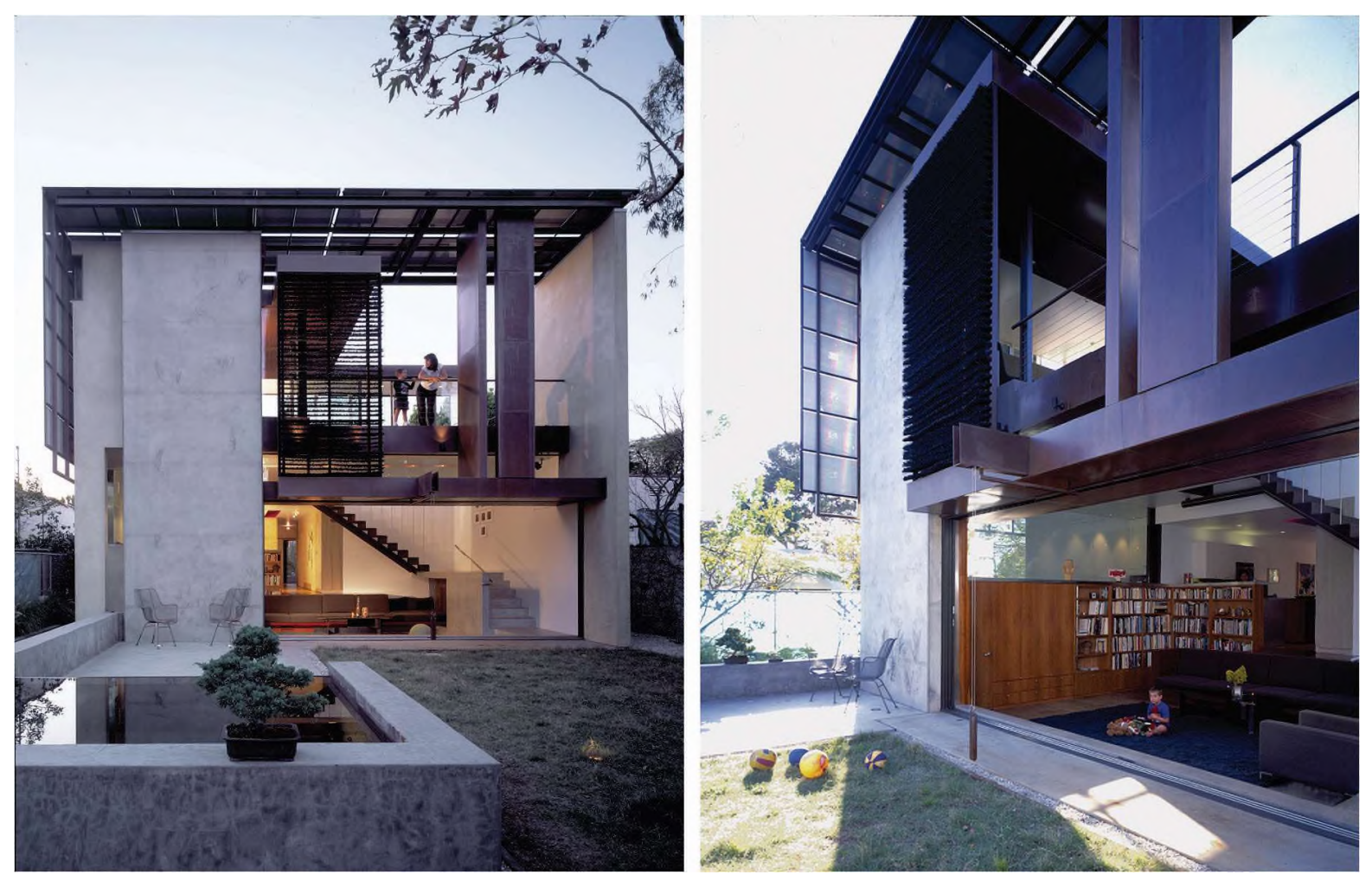

Fig. 6. Imagen exterior de la Solar Umbrella House en la que se observa el sobretecho fotovoltaico que la caracteriza. El gran paraguas solar colabora con la concreción de una gran fluidez entre espacio interior y exterior. Fuente: http://brooksscarpa.com/solar-umbrella-house

Los casos analizados, que han sido seleccionados con el objeto de mostrar la diversidad de escalas posibles de integración arquitectónica fotovoltaica y demuestran que resulta técnicamente viable generar energía en la envolvente de los edificios.

De esta manera se conjugan diseños técnicos impecables con altos valores estéticos, basados en fuertes principios éticos ambientales. 


\section{CONCLUSIONES}

La biomimética pone a disposición de la arquitectura, el diseño y la construcción un abanico de herramientas para retornar a una instancia de mayor sustentabilidad entre el medio natural y artificial. Representa un abordaje de la sustentabilidad que intenta inspirar formas, procesos y sistemas como lo hace la naturaleza, con total eficacia y eficiencia.

Todo diseño que aspire a ser biomimético debe prever o proponer un uso de la energía solar, dado que de ella derivan todas las demás fuentes de energía. La fotosíntesis representa el proceso que inspira la captación solar fotovoltaica. En la actualidad la posibilidad de alimentar energéticamente a los edificios con el sol resulta técnicamente posible y parcialmente viable desde el punto de vista económico.

Resultan innumerables los casos de integración arquitectónica de edificios que incorporen en su envolvente la captación solar. A modo de ejemplo se han analizado alguno de ellos, tratando de abarcar distintas tipologías arquitectónicas y escalas de intervención. En todos los casos se observa la combinación del uso de la energía solar con otros criterios de sustentabilidad, aunque en general se observa que la propuesta fotovoltaica resulta el único rasgo de diseño biomimético.

Con un adecuado diseño la energía solar se convierte en una expresión estética agradable de principios éticos ambientales y que favorecen la difusión de la conciencia ecológica en la sociedad.

El hombre desde el principio de los tiempos ha tratado de transformar la naturaleza para mejorar su calidad de vida, en general sin tener en cuenta las consecuencias ambientales negativas de sus acciones. En la actualidad la conciencia ambiental es cada vez más extendida, instalándose fuertemente el paradigma del cuidado y preservación del ambiente, como el único sostenible.

La biomimética representa un nuevo enfoque en una sociedad acostumbrada a dominar o transformar la naturaleza. La posibilidad de aprender de la naturaleza e inspirarse respetuosamente en sus formas, procesos y sistemas, representa un nuevo paradigma en pleno desarrollo, que augura un futuro potencialmente más armónico entre naturaleza y sociedad.

\section{BIBLIOGRAFÍA}

Benyus, Janine M. (2012). Biomimesis. Cómo la ciencia innova inspirándose en la naturaleza Barcelona (España). Tusquets Editores S.A.

Braungart, M. y Mcdonough, W. (2005). Cradle to cradle. Rediseñando la forma en que hacemos las cosas. Madrid, España: McGraw Hill.

Brooks + Scarpa. Architecture Landscape Urban Design. Página oficial. Recuperado de www.brooksscarpa.com

Chivelet, N., \& Fernández Solla, I (2007). La envolvente fotovoltaica en la arquitectura. Barcelona, España: Reverté.

Costa Duran, S. (2007). Casas ecológicas. Barcelona, España: Editorial Reditar Libros, S.L.

Costa Duran, S., Baraona Pohl, E. y Bollini, L. (2010). Viviendas ecológicas. Dreem Green. Barcelona, España: Editorial Reditar Libros, S.L.

FENERCOM Fundación de la Energía de la Comunidad de Madrid (2009) Guía de integración solar fotovoltaica. Madrid Solar: Consejería de Economía y Hacienda. Recuperado de www. fenercom.com

Garrido S., Lalouf A., Moreira, Ana Josefina (2014). Tecnologías para la inclusión social y dinámicas desarrollo sustentable. Análisis socio-técnico de experiencias de desarrollo local basadas en el aprovechamiento de energías renovables. Astrolabio. Nueva Época. Número 12.

HHS. Hegger, Hegger, Schleiff. Architekten. Página oficial. Recuperado de hhhs.ag

IRENA International Renewable Energy Agency (2016) Estadísticas de energía renovable 2015. Recuperado de www.irena.org

Martínez Lapeña \& Torres Architects. Página oficial. Recuperado de www.jamlet.net 
Pastorelli, G. (2010) Centro Tecnológico Palmas Altas / Rogers Stirk Harbour \& Partners - Vidal y Asociados arquitectos. Plataforma Arquitectura. Recuperado de http://www. plataformaarquitectura.cl

Pearce, Peter (1979). Structure nature is a strategy for design. Cambridge (Massachusetts, USA). The MIT Press.

Pilar, Claudia. (2017) Casos de integración arquitectónica de sistemas fotovoltaicos. Un abordaje matricial desde las formas, los usos y los significados. ARQUISUR REVISTA, AÑO 7, No 11. Julio de 2017. Pág. 80 a 92. Revista Digital: ISNN 2250-4206. Impreso PDF: ISNN 1853-2365. https://bibliotecavirtual.unl.edu.ar/publicaciones/index.php/ARQUISUR/issue/view/548.

REN 21- Renewable Energy Policy Network for the 21st Century (2014). Informe del Estado Global 2013 Energías Renovables. Recuperado de www.ren21.net

REN 21- Renewable Energy Policy Network for the 21st Century (2016). Informe del Estado Global 2015 Energías Renovables. Recuperado de www.ren21.net

Rogers, Stirk y Harbour + Partners. Página oficial. Recuperado de www.rsh-p.com

Tofler, A. (1980). La tercera ola. Colombia. Plaza y Janes Editores.

Vedoya, Daniel E. (2014). La transposición tecnológica. Introducción a la génesis de los procesos tecnológicos - Saarbrücken (Alemania). Editorial Académica Española.

Wagensberg, Jorge (2002). Si la naturaleza es la respuesta, ¿cuál era la pregunta? Barcelona (España). Tusquets Editores S.A. 